\title{
Negociaciones (trans)culturales en el Mediterráneo. Inmigración y 'clandestinidad' en la música popular española contemporánea
}

\author{
Birgit MERTZ-BAUMGARTNER (Innsbruck)
}

\section{Summary}

For many decades, Spain has been a country of emigration. Its transformation to a country of immigration (e.g. from Latin America and Africa) is a quite recent phenomenon, which only started in the 1970s due to the economic upturn of the country. From 1991 onwards (signing of the Schengen Agreement) the 'illegal' immigration across the Strait of Gibraltar has increasingly been perceived as a problem.

Spanish popular music is a fine seismograph of social changes, such as the increase of immigration. The first musical productions reflecting on ('illegal') immigration date from the early 1990s, such as Barricada's "Oveja negra”, El Chojín’s "Ponte en mi piel” and "Sí, Buana”, or Nach’s “Tierra prometida". Based on a corpus of 50 songs of different musical styles (rock, rap, world music), this article aims at investigating the key thematic lines in songs about 'illegal' immigration: the subalternity of the migratory subject; the fraught relations between the migrant subject ('I') and the Spanish 'you', relations characterized by prejudice, racism, and exclusion; finally, the perspective of a 'we' in a transcultural Spanish society.

\section{Introducción}

Los historiadores y sociólogos coinciden en afirmar que España no es un típico país de inmigración (como Francia o Alemania), sino un país de emigración. La historia social española del siglo XX se caracteriza por unos largos períodos de emigración de españoles hacia América Latina y, a partir de 1960, a otros países europeos como Francia, Alemania, Suiza o Inglaterra. Ya en las primeras décadas del siglo XX dos millones de españoles dejaron el país en búsqueda de trabajo y una situación económica mejor (cf. Bernecker 2006, 309). Al motivo económico se juntó, durante la guerra civil española, la persecución política que empujó a unos 300.000 republicanos al exilio. Entre 1946, año a partir del que el régimen franquista permitió oficialmente la emigración, y 1970 unos 900.000 españoles se fueron del país por motivos políticos y económicos (cf. Bernecker 2006, 312). 
Con el auge económico de los 80 y la entrada en la Comunidad Europea (en 1986) la situación migratoria cambió y España se transformó - al menos hasta la crisis financiera de 2008 - de un país de salida en un país de acogida (cf. Kreienbrink 2008, 243). Acogió, primero, a inmigrantes procedentes de países latinoamericanos que se refugiaron de las dictaduras en Argentina, Chile o Uruguay, o emigraron por razones económicas; segundo, a migrantes de países norteafricanos y subsaharianos y, tercero, a emigrantes este-europeos (cf. Sánchez Fuarros 2013, 144). Algunos geógrafos sociales hablan de un "boom inmigratorio" que se inició en los años 90 y persistió durante los años 2000, boom que situó a España como segundo receptor neto de inmigrantes a nivel mundial (cf. Ortega-Rivera/Domingo i Valls/Sabater Coll 2014, 2).

A partir de 1991, año en que se firmó el Acuerdo de Schengen y se introdujo un visado obligatorio para muchos países del sur global, la inmigración ilegal - en los enclaves españoles de Ceuta y Melilla y a través del Estrecho de Gibraltar - empezó a manifestarse como 'problema'. España (con el apoyo financiero de la Unión Europea) reaccionó ante la nueva situación y empezó con la construcción de las primeras vallas de 'protección' entre Marruecos y España. ${ }^{1}$ Aunque, en el presente, la llamada "ruta del Mediterráneo Oeste" resulta mucho menos frecuentada que la "central" hacia Italia (http://frontex.europa.eu/ trends-and-routes/migratory-routes-map/), los asaltos a la valla de Ceuta a partir de febrero 2017 nos recuerdan que la situación aún se mantiene sin solución. Además de las construcciones fronterizas, fueron adoptadas y reformadas varias leyes durante los años 90 y 2000 para arreglar, controlar y restringir la inmigración del sur (cf. Kreienbrink 2008, 250-254). Mencionemos sobre todo la modificación de la Ley de Asilo en 1994 que se inscribió en la política de cierre de fronteras de esta época, así como la reforma de diciembre 2000 (Ley Orgánica 8/2000) que aportó varios endurecimientos como la exclusión de inmigrantes ilegales de algunos derechos fundamentales (derecho de reunión, de formación de sindicatos, etc.).

La alta homogeneidad 'cultural' de la época franquista (controlada y mantenida de manera dictatorial) se transformó velozmente en pocas décadas (a partir de 1975) en una diversidad 'cultural' impresionante. "La diversidad cultural se ha convertido en el término de unas pocas décadas en una realidad de la Península Ibérica que transforma fundamentalmente la comprensión cultural de 'lo nacional'." (Sieber/Abrego/Burgert 2015, 19) Aunque la migración haya cambiado nuevamente de sentido a partir de 2008 con la crisis financiera, la diversidad 'cultural' como realidad de la sociedad española persiste.

La música popular española se revela como fino sismógrafo de los cambios y transformaciones sociales arriba mencionados, tematizando y reflejando la transformación de España en país de acogida, la inmigración ilegal, la fortificación de las fronteras, las leyes de extranjería y la diversificación étnica de la sociedad española. Ya a principios de los años 90 aparecieron las primeras producciones que tematizaron el nuevo fenómeno de inmigración del sur global hacia España. "Oveja negra" de la banda rock Barricada, así como "Ponte en mi piel" y "Sí, Buana" del rapero El Chojín ${ }^{2}$ - todos del año 1992 - pueden servirnos de ejemplos. ${ }^{3} \mathrm{El}$ corpus en que se basa este estudio - establecido por la autora del artículo - cuenta con unas 
50 producciones de estilos musicales diversos, con un predominio del rock, del rap y de la música fusión (cf. lista en anexo). Se han incluido en la muestra canciones (en un sentido muy amplio) producidas entre 1990 y 2017 en las que aparece el tema de la inmigración y de los cambios sociales provocados por ella. Podemos agrupar estas canciones - en cuanto a los temas tratados - en tres grandes grupos. En el primer grupo, están reunidas las canciones en que se manifiesta un 'yo' lírico inmigrante que medita sobre su existencia de sujeto migratorio. En este tipo de canciones predominan temas como las razones de la emigración, la vida precaria en España y la subalternidad del 'yo' migrante. El segundo grupo, reúne las canciones que se enfocan no exclusivamente en el 'yo' migrante, sino en situaciones de encuentros entre inmigrantes y españoles. Se interesan por las 'zonas de contacto' (contact $z_{\text {zones }}^{4}$ ) en que se realizan los encuentros (p.ej. la frontera, el control de papeles, el mercado del trabajo), encuentros que muchas veces se caracterizan por su asimetría de poder y su potencial conflictivo. Los temas dominantes son los perjuicios frente a los inmigrantes, el racismo y la exclusión. En el tercer grupo, finalmente, agrupamos las canciones que se distancian de la idea de que los flujos migratorios conllevan automáticamente un 'choque cultural' y que desarrollan la visión de una España multiétnica. En estas canciones la idea de un "clash of civilizations" (en el sentido de Samuel P. Huntington) provocado por la inmigración está sustituida por la idea de una transculturación y una diversidad 'cultural' que caracteriza todas las sociedades contemporáneas. Para evitar la simple enumeración de ejemplos, optamos por el análisis detallado de una canción (temáticamente) representativa en cada grupo.

En cuanto al enfoque teórico, el artículo se nutre de los estudios postcoloniales y de algunos de sus conceptos claves, como la subalternidad (Gramsci, Spivak), los estereotipos culturales y las estrategias (discursivas) de degradación (Memmi, Fanon), así como la transculturación (Ortiz, Welsch). El análisis de las canciones sigue el modelo triádico propuesto por Ursula Mathis-Moser en 1984 y ampliado por Andrea Oberhuber en 1995. Incluiremos en nuestros análisis, en correspondencia a los componentes del género multimodal, letra, musicalización e interpretación, así como - cuando nos parece de valor semántico - el videoclip.

\section{YO. Hacia la "Tierra prometida” (Nach 2005)}

En su análisis de rock-pop contemporáneo español, Martínez Casas constata que el carácter enunciativo de las canciones analizadas es mayoritariamente (inter-)personal, (inter-)personalidad que se manifiesta en la alta frecuencia con que se utiliza 'yo' (me, mí, yo) y 'tú' (te, tú): "[E]l 'yo' aparece en un mínimo del $73 \%$ de las canciones analizadas y el 'tú', en un 58\%." (Martínez Casas 2017, 3-4) También en nuestra muestra llama la atención la fuerte presencia del 'yo' lírico que - en este caso - adopta la perspectiva de un inmigrante en España, independientemente del artista que puede ser español ${ }^{6}$, mestizo o migrante. 
En su mayoría, no se trata de un 'yo' individualizado - hay una sola producción en el corpus en que el 'yo' tiene nombre (La Fuga, "Vientos del sur", 2001) - sino más bien de un 'yo' migrante prototípico como si se quisiera pintar la condición de vida del migrante en general. Varias veces el 'yo' compara explícitamente su situación existencial con la de otros inmigrantes de otras nacionalidades para subrayar el carácter ejemplar de sus palabras.7

A través de la introspección que permite la 'narración' en primera persona, se despliegan ante nuestros ojos los motivos de la emigración (pobreza, hambre, guerra), las ilusiones y desilusiones de la 'tierra prometida', Europa, así como el destino actual del migrante. Si la migración en sí ya es altamente dolorosa y no tiene nada que ver con un viaje voluntario, la existencia, muchas veces clandestina, del migrante lo es todavía más. Se repite en varias canciones que la migración no se acaba con la llegada al territorio ajeno, sino que continúa en el país de acogida. Ser migrante significa ser en perpetuo movimiento y no poder descansar. "Correr es mi destino", canta Manu Chao en "Clandestino", "ando sin papeles / [...] me escondo cuando viene inmigración", repite Che Sudaka en "Sin papeles" y Jesnac rapea en "Idas y Venidas"10: "Yo ya no sé dónde ir / si no tengo dónde volver / yo ya no quiero caminar / si no hay nadie a quien ir a ver." A la movilidad forzada y onerosa, se añaden la inseguridad social ligada al estatus de 'ilegalidad' y la explotación en el mercado de trabajo.

El primer ejemplo que queremos analizar en este contexto es "Tierra prometida" (2005) $)^{11}$ de Nach - un rapero y poeta nacido en Albacete, un rapero blanco, sociólogo de formación, de nombre real Ignacio Fornés Olmo. "Tierra prometida", que aparece en el álbum Ars magna en 2005, está muy arraigada en el ámbito político-social de los años 2000. Se refiere explícitamente a la Ley Orgánica 8/2000, la "ley de extranjería" como se llama en la letra que se adoptó tras la victoria del Partido Popular en las elecciones generales de 2000 que le dieron mayoría absoluta. Se trata de una ley altamente criticada y calificada de retroceso por sus endurecimientos en cuanto a la situación de los inmigrantes ilegales.

El 'yo' ya se manifiesta en la primera palabra de la canción y revela en el primer verso su identidad de migrante que viene a España de una tierra natal hostil. A nivel musical, la tierra natal está presente en el preludio de la canción a través de unos bongos africanos a los que se añaden, al empezar el canto del rapero, la batería y el bajo que dan al rap su ritmo. ${ }^{12}$ La canción se caracteriza por una intensa presencia del 'yo' - que se traduce en pronombres personales (yo, me), posesivos (mi/s, míos) utilizados con gran frecuencia y también a través de las formas verbales. Esta presencia se condensa en el penúltimo verso donde leemos: "Aquí estaré / Vine para quedarme."13

"Las pateras no son sólo noticias que ves en la tele / hay historias detrás", canta El Chojín en "Ponte en mi piel"14. "Tierra prometida" de Nach cuenta una de estas historias; sigue la cronología del movimiento migratorio del 'yo' lírico (dejar su país; estar en España; quedarse en España) y se refiere por eso a tres tiempos diferentes: el pasado, el presente y el futuro. Así, se explican, en pocas palabras, las razones de la emigración ("las cosas van mal", "violencia", "pobreza", "El paisaje gris de mi país me obligó a huir"), así como las condiciones de la migración ("cruzar el estrecho en patera", "odisea"). Le importa mucho al 'yo' lírico poner de relieve el carácter involuntario y forzado de la migración, lo que se refleja también 
a nivel formal. Nach recurre a una figura retórica de repetición (cf. Pujante Cascales 2009) el homeotéleuton - que además de la rima pareada ('porvenir', 'sobrevivir') e interior ('salir', 'porvenir') repite los mismos fonemas finales en casi todas las palabras utilizadas: "tuve que salir, buscarme un porvenir / resurgir, resistir y conseguir sobrevivir." Se produce así una aceleración e intensificación del ritmo que confiere importancia semántica a cada una de las palabras. Emigrar es una decisión inevitable para el 'yo', representa su única posibilidad de tener un futuro, de sobrevivir y nutre su esperanza de 'renacer' en el país de acogida.

La parte principal de la canción se centra en el presente, en las condiciones de vida como inmigrante ilegal en España (no tiene papeles, hace trabajos sucios, es explotado, vive en un "zulo oscuro" por falta de dinero) así como en las experiencias sociales que tiene ("pocos tienden su mano”). Su 'otredad', que se manifiesta en el color de su piel, en las diferencias de lengua, de religión y de costumbres, provoca miedo y rechazo y causa su marginación en la sociedad española. De nuevo, Nach se sirve de una figura retórica de repetición (sintáctica esta vez) - la anáfora - para fijar la atención del auditorio en el mensaje central, la lucha cotidiana del migrante contra un entorno hostil: "me peleo [...]" (repetido tres veces). Llama la atención que la guitarra eléctrica repite, a lo largo de la canción y sin variación ninguna, la misma serie de tonos provocando así una monotonía hostil que, junto con el texto, caracteriza la vida cotidiana del clandestino.

La última parte está consagrada al futuro del migrante, lo que se refleja en las formas verbales utilizadas (p.ej. "aprenderé”, "estudiaré”, "compartiré”). Expresa la voluntad del migrante de adaptarse a su país de acogida, pero también la necesidad de que la sociedad española se abra a su nueva diversidad 'cultural' (“jacostúmbrate!”). Cabe notar que en la última parte de la canción - después de la frase "sí me quedaré en España, si me dejan vuestras calles" - (en la grabación) se entienden varias voces diferentes (hombres y mujeres de lenguas diferentes) que subrayan las experiencias articuladas por el 'yo'. Estas voces se mezclan con la de Nach en la última estrofa y forman un coro (heterogéneo y desordenado) que representa el futuro de la nueva España.

\section{TÚ. "Me dicen el clandestino / por no llevar papel” "“Clandestino", Manu Chao, 1998)}

Varias canciones del corpus se enfocan en las relaciones entre españoles y migrantes y las describen, casi exclusivamente, como negativas. Tematizan que el migrante, desde el principio, se ve confrontado con prácticas de exclusión que operan a nivel nacional e interpersonal. Se refieren muy concretamente al 'régimen fronterizo' establecido por España a partir de los 90, régimen fronterizo que incluye todas las medidas institucionales, administrativas, legislativas y técnicas que sirven al control de la frontera (cf. nuestra introducción). "Tierra prometida" (como ya hemos visto) hace referencia a la ley de extranjería que intenta regular restrictivamente la inmigración clandestina, así como a la guardia costera que vigila las costas españolas para frenar o impedir la inmigración ilegal. En "Víctima" (2006) ${ }^{15}$, que sale 
casi en la misma época, Barricada, grupo conocido por su compromiso social, tematiza la fortificación de las fronteras españolas y las inversiones públicas excesivas en este proyecto. Leemos en la letra: "millones y miles de millones de alambres / de verjas de papeles y de ofensas / de uniformes de fronteras de banderas / y demás mierdas / de dinero destinado a que no molestes". ${ }^{16}$ En la misma canción, el grupo señala y critica la 'marcación' del inmigrante como inmigrante, o mejor dicho, su 'producción' por unas prácticas sociales como la toma de las huellas digitales ("Marcao con un solo dedo / marcao siguiendo tus huellas”). Esta crítica de prácticas de control que 'usurpan' el cuerpo del migrante es todavía más fuerte en "Oveja negra" 17 , canción publicada más de diez años antes, en 1992, en el álbum Balas blancas. Recordemos que en 1991 España firmó el acuerdo de Schengen y se introdujo el visado obligatorio para muchos inmigrantes del sur global. Con esto empezó la preocupación de España y de la Unión Europea por sus fronteras del sur, la primera valla en Ceuta se construyó en 1993.

"Oveja negra" cuenta una situación ficticia de control fronterizo, en el que el guardia civil - el 'yo' de la canción - ordena a sus colegas el registro de un inmigrante con las palabras siguientes: "Hacerle fotos, tomarle las huellas / miradle bien los dientes / Si se resiste rompedle la cabeza, / la rutina de siempre.” Estos versos sirven de introducción a la canción y están repetidos una segunda vez en su última parte, lo que subraya su importancia. Para que no se produzca ningún malentendido, el estribillo "Balas blancas, balas blancas, para la oveja negra” aclara sin equívoco la posición crítica de la canción frente al comportamiento del guardia civil. En los colores opuestos 'blanco' y 'negro' se refleja la situación de 'contacto’ entre el guardia civil español y el inmigrante africano en una zona de contacto muy concreta que es la frontera. La relación se caracteriza por una fuerte asimetría de poder que confronta al inmigrante indefenso, la "oveja negra", con un representante del Estado que actúa con exagerada violencia ("balas", "rompedle la cabeza”). "Oveja negra” no es la única canción que tematiza la violencia inaceptable de los controles fronterizos, encontramos el mismo tema también en otras canciones producidas entre 1992 y $2003^{18}$ : "Sí, Buana" (1992) de El Chojín, "Qué se te escapa el negro" (1996) de Ella baila sola, "No os dejan entrar" (1999) de Frank T. o "Sin papeles" (2003) de Che Sudaka.

A nivel interpersonal, la exclusión y la marginación del migrante se traducen en un discurso de desprecio y de degradación en el que dominan denominaciones personales despectivas ("negro", "extranjero", "forastero", “intruso") y prejuicios (ser inmigrante equivale a ser criminal) ${ }^{19}$ así como en un discurso meramente racista ${ }^{20}$. Es llamativo que varias canciones reproducen este discurso despectivo y racista, pero sin que el auditorio pueda comprenderlas como afirmativas. Para ilustrar como una canción reflexiona sobre mecanismos discursivos de exclusión y los critica, nos servimos del gran éxito de Manu Chao "Clandestino" $(1998)^{21}$.

Al igual que en “Tierra prometida” el 'yo' lírico se manifiesta desde la primera línea ("Solo voy"), reclamando así su individualidad y su derecho a la palabra. Se trata de un 'yo' inmigrante que lleva una vida penosa y solitaria en "una ciudad del norte" que puede ser Madrid, Barcelona u otra. Se caracteriza por su 'invisibilidad', su existencia fantasmal, 
'subterránea', en escondite - evocada en la canción por la comparación a "una raya en el mar" -, en una sociedad española que se mantiene indiferente ante el destino del migrante. Mientras que el 'yo' en el acto de decirse 'yo' se reclama como sujeto, los demás le llaman "clandestino" cortándole así su carácter individual y su historia personal. A través de un discurso del que el 'yo' está excluido, del que es objeto pasivo y que se caracteriza por prejuicios y adscripciones negativas, se construyen su 'clandestinidad' e 'ilegalidad'. Estas adscripciones se formulan explícitamente en la letra: "me dicen el clandestino", "Mi vida va prohibida / dice la autoridad". Como sabemos gracias a los estudios de géneros es la repetición de una norma, de un juicio, de unos valores atribuidos lo que garantiza su sedimentación y les confiere poder. Es este proceso de 'petrificación' de juicios y prejuicios garantizado por la repetición discursiva lo que expone Manu Chao en la canción. La repetición domina la letra ("me dicen el clandestino" se repite tres veces, "clandestino/clandestina" nueve veces) y todavía más la estructura musical. A lo largo de la canción se repite la misma cadencia - tónica, subdominante, dominante, tónica (I - IV - V - I) - en fa sostenido menor (tónica), si menor (subdominante) y do sostenido mayor con séptima $\left(\mathrm{C} \#^{7}\right)$ (dominante) sin efectuar una modulación en otra tonalidad. La única variación que podemos observar es la reducción a la fórmula dominante - tónica en los versos "Mano negra, clandestino / peruano, clandestino / africano, clandestino / marihuana ilegal”, variación que fija nuestra atención en 'clandestino' e 'ilegal' (en fa sostenido menor). La canción busca el efecto de monotonía, en el patrón rítmico constante, en el rasgueo de la guitarra y a través de la repetición textual.

El migrante, como lo evoca Manu Chao en "Clandestino”, se parece mucho al subalterno, descrito por Antonio Gramsci en sus Cuadernos de la cárcel (1929-1935), y décadas después, por Gayatri C. Spivak en su artículo "Can the Subaltern Speak?" (1988). Para Gramsci, los subalternos no pertenecen a ningún grupo hegemónico, no tienen organización política y no disponen de una consciencia de clase que pueda darles unidad. Carecen de una representación política y de una voz solidaria capaz de reclamar y defender sus derechos y constituirlos como sujetos políticos (cf. Steyerl 2008, 8-9). La teórica postcolonial Gayatri C. Spivak retoma en 1988 la noción de subalternidad para caracterizar a personas que no tienen ningún espacio de movimiento ni margen de acción (agency) y por eso carecen de toda posibilidad de cambiar su situación (cf. Steyerl 2008, 121). Además, estos subalternos no disponen de ninguna posibilidad de realizar unos "actos de habla". Como Spivak explica en "Subaltern Talk" (1993) la pregunta provocadora formulada en el título de su ensayo "Can the Subaltern Speak?" no puso en cuestión la capacidad de hablar de los subalternos, sino su posibilidad de hablar y de ser entendido: "By 'speaking' I was obviously talking about a transaction between the speaker and the listener." (Spivak, en Landry/Maclean 1995, 289) El acto de habla incluye no solamente el acto de hablar sino también el acto de ser escuchado y entendido. Y, como lo ponen de relieve María Do Mar Castro Varela y Nikita Dhawan, el acto de ser escuchado y entendido se rige por una estructura hegemónica (cf. Do Mar Castro Varela/Dhawan 2005, 76).

El clandestino de la canción de Manu Chao no tiene voz propia, es sometido a los discursos despectivos sociales y carece de todo margen de acción. No obstante, el 'yo' subalterno de la 
canción no es solitario, sino que comparte su destino con todos los migrantes mencionados en el texto: "peruano", "africano", "argelino", "nigeriano", "boliviano". En el contexto de estas reflexiones, el video-clip original (de $1998^{22}$ ) resulta particularmente interesante. Ensambla una serie de imágenes que presentan - en alternancia con el artista que interpreta la canción - a personas de orígenes diversos o, mejor dicho, sus rostros 'de color'. Recurre a primeros planos o semiprimeros planos (close up shot, semi close up shot ${ }^{23}$ ) sea para introducirnos en la psicología de las figuras, mayoritariamente tristes, desesperadas, sea para concentrar nuestra atención en unos objetos (un pasaporte, una tarjeta de identidad, una partida de nacimiento, unas fotos de familia, un dibujo) que conforman su existencia en la emigración. Resulta interesante el montaje de imágenes del artista y de retratos de migrantes, montaje que sugiere que el artista forma parte del grupo de los migrantes. La superposición estética de las imágenes de clandestinos y del artista mismo puede justificarse por la biografía de Manu Chao: sus padres tuvieron que dejar la España franquista, se instalaron en París, donde nació Manu Chao que hoy en día vive en París y en Barcelona. Al mismo tiempo, es muy evidente que la situación de vida del artista no corresponde en nada a la de los clandestinos mostrados en el video-clip. Poniéndose en medio del grupo de los inmigrantes (cf. abajo), Manu Chao se pone en escena como portavoz de los que no tienen voz. ${ }^{24}$

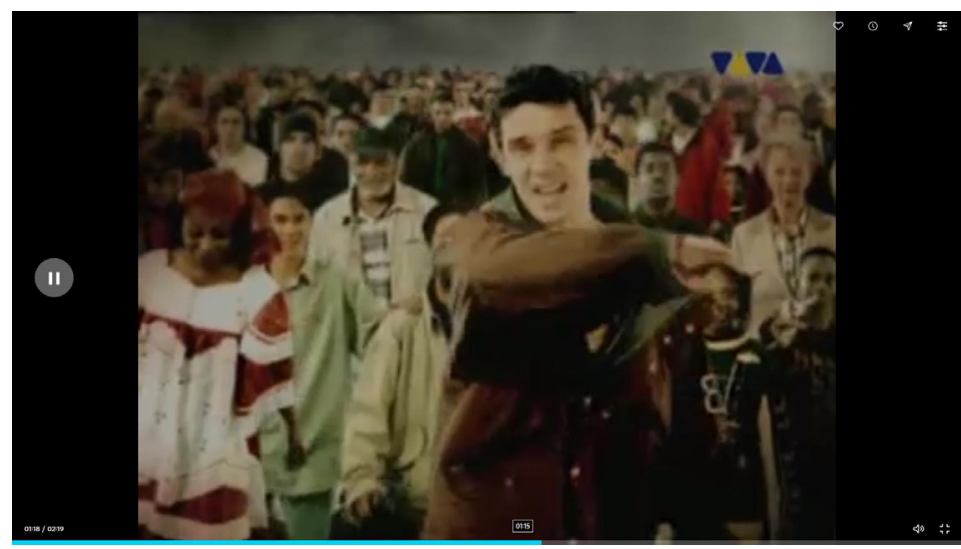

Figura 1: Captura de pantalla del video oficial "Clandestino”, 1:18

NOSOTROS. “¿Cómo puedo hacerles entender / que la naturaleza es un DJ sobre una mesa de mezclas?” (El Chojín, "Ponte en mi piel”, 1992)

La cita inicial que sacamos de la canción "Ponte en mi piel” de El Chojín, refleja la necesidad, concienciada por el artista, de redefinir la 'identidad' española que en las últimas décadas del siglo XX empezó a cambiar su rostro homogéneo nacional a uno heterogéneo transnacional. "Ponte en mi piel" refleja la convicción de que en estos años ya no sería posible mantener la visión de una España blanca y católica, así como la idea de pureza, sino que tendría que desarrollarse la imagen de una España multiétnica, transcultural, mezclada, mestiza. 
Notemos que la pluralización 'visible' de España empezó muy tarde y que, a principios de los años 90, ni siquiera las grandes ciudades tenían un rostro verdaderamente plural. Dice El Chojín en una entrevista: "En España en los años ochenta no había negros." (Green 2011, $178)^{25}$ Stuart Green, el entrevistador, subraya que - por ese retraso - faltaba en España también "un discurso que dé cuenta de la diversidad étnica interna" (Green 2011, 167).

No es casual que en el ámbito de la música popular las reflexiones esbozadas se inicien con la voz del rapero El Chojín. El artista, de padre ecuatoguineano y de madre española, conoce por su propia biografía lo que significa nacer en España y, sin embargo, ser considerado como 'diferente' por el color de la piel. Cuenta, en la entrevista citada, que ya a los 13 años se dio cuenta de esta 'diferencia' cuando la policía empezó a pararle sin motivo. ${ }^{26}$ Para El Chojín, el rap, que para él tiene que ser contestatario, es particularmente apto para desarrollar "otra visión de la sociedad"27.

Una visión alternativa de la sociedad española de finales del siglo XX se pinta por ejemplo en las canciones de rap de Frank T., otro rapero negro, nacido en Zaire (hoy República Democrática del Congo) que vino a España con dos años y se crio en Torrejón, cerca de Madrid. Como El Chojín, describe sus propias experiencias de no-pertenencia y de exclusión que, entre otras, se expresan en preguntas como estas: "¿Cómo puedes ser tan negro?”, “¿Hablas africano?”, “¿Por qué hablas perfectamente español?” (Green 2011, 170), preguntas benévolas, pero discriminatorias que ya discutió Frantz Fanon en Peau noire, masques blancs ${ }^{28}$. De la conciencia de nunca ser considerado como español 'verdadero' - por el color de su piel - empezó a autodesignarse, con mucha ironía, como " $\mathrm{X}$-isiano"29, equis, de identidades cruzadas, de pertenencias múltiples y transnacionales. De aquí, salió en 1998 la canción de rap "La rebelión de los x’isianos"30 (con El Chojín y El Meswy, "MCs que se rebelan junto a mí"), que es una larga reflexión sobre la identidad transcultural. ${ }^{31}$ Parte de su propia biografía en la cual la diferenciación entre un 'aquí' y un 'allá' no funciona: está socializado en España, habla la lengua de aquí, se parece a los de allá y tiene padres de allá. Tanto de aquí como de allá, define su identidad (en la canción) como "producto de una ecuación sin resultado / una $\mathrm{X}$ al final de una operación que nunca nadie ha terminado"; en otros términos, se trata de una identidad cuyo proceso de transformación o de transculturación todavía no se ha parado. El 'yo' del rap y el rapero mismo se consideran como representantes típicos de una sociedad migratoria contemporánea, una España transcultural que, durante largas épocas, había reprimido y negado su diversidad. En este contexto muy llamativo que El Chojín, en su guest rap (en "La rebelión de los x'isianos"), recuerda el pasado árabe de España: "[T]ienes que saber qué eres, y eres medio moro." En lo que sigue, Frank T. se reclama "de ¡ningún país!", "de ningún lado” y sustituye la idea de una pertenencia territorial y nacional por una pertenencia artística al mundo del rap: "[M]i país es el estado mental donde las rimas me he currado."

Su visión de la España del nuevo milenio, de la que se considera ser el representante típico ("Yo soy el ejemplo"), se articula lo más explícitamente en "La Nueva España" (2006) 32. Aquí, desarrolla la idea de un país multiétnico ("tiene más de un color"), multireligioso y multilingüe en que "Distintas hablas, etnias, religiones / Cohabitan"333, una España - como 
dice el estribillo - levantada por inmigrantes ("la levantan inmigrantes"). En este "crisol" (o podríamos servirnos de la imagen de Fernando Ortiz, el fundador del concepto de la transculturación, "ajiaco"; Ortiz 1940) las tradiciones españolas - y Frank T. cita las más estereotipadas, la tauromaquia y el flamenco - se mezclan con "mil hablas y colores", con todos los aportes de 'afuera'. Llama la atención que las nociones de 'mezcla' y de 'contaminación', frecuentemente utilizadas para caracterizar a la Nueva España, tienen una connotación positiva en Frank T. El 'yo' lírico pone de relieve que aquí se siente "acompañado" por "tipos que se parecen a mí”, lo que subraya la sensación de solidaridad que reúne a los diferentes grupos de migrantes (latinos, africanos, caribeños). Los X'isianos - concepto repetido en esta canción ${ }^{34}$ - se dicen (¿por primera vez?) 'nosotros', lo que se traduce en el uso frecuente de formas verbales de la primera persona del plural: "naciéramos", "podríamos", "cambiaremos". "Europa está cambiando", concluye el rapero.

\section{Conclusión}

La música popular española, como la literatura y el cine, aborda el tema de la inmigración legal e ilegal en España a partir de los años 90 hasta hoy en día y hace así visible y audible a un grupo que mayoritariamente carece de visibilidad y audibilidad sociales. Con sus referencias críticas a actos políticos concretos, como el levantamiento de vallas y muros fronterizos, la aprobación de leyes de inmigración restrictivas o la instalación de SIVE en las costas españolas, la música popular se revela un terreno perfectamente válido para estudiar la realidad social española. Al mismo tiempo representa una intervención artística en el discurso político y social dominante. En estas intervenciones se da voz a los destinos e historias individuales de los 'inmigrantes' y 'clandestinos' que - en la prensa o la tele - se perciben mayoritariamente como masa desindividualizada. Además, se formula una posición crítica frente a unas sociedades europeas en las que se establecen más y más partidos populistas de derecha y en las que se manifiestan posturas de exclusión y de racismo. Llama la atención que el número de canciones antirracistas es particularmente alto. Además, la música popular del período discutido se muestra sensible a los cambios sociales que resultan de la inmigración, como la transformación de España en una sociedad plural y transcultural.

Nos parece interesante mencionar que los temas arriba resumidos no conocen una sucesión temporal sino que coexisten desde 1990 hasta hoy en día. Dicho de otra forma, las ideas del mestizaje, de la transculturación y de la transnacionalidad no son fenómenos actuales sino que están ya presentes en las canciones de los 90 . No asombra en este contexto que el rap contestatario esté particularmente atento a los temas ligados a la migración y se comprometa especialmente en la deconstrucción de las ideas de una identidad española homogénea y pura. "La naturaleza es un DJ sobre una mesa de mezclas." 35 


\section{Notas}

1 Hoy en día, la línea fronteriza consiste de vallas paralelas de actualmente tres metros de altura, seis metros proyectados, con alambres de púas encima, varios puestos alternados de vigilancia, cámaras de vigilancia y - bajo el suelo - una red de sensores electrónicos de ruido y movimiento.

2 El Chojín es uno de los raperos españoles más destacados y co-autor de una historia del rap español (El Chojin/Reyes 2010).

3 Llama la atención que la música popular española que tematiza la inmigración ha sido muy poco estudiada (según nuestros conocimientos) hasta hoy en día. Y eso muy al contrario del cine español de la misma época que se dedica al tema de la migración que es objeto de muchos estudios científicos (cf. entre otros Iglesias Santos 2010; López-Aguilera 2010; Deveny 2012; Peralta García 2016). En el ámbito de la etnomusicología destacan las publicaciones de Isabel Llano Camacho (2015) y de Ínigo Sánchez Fuarros (p.ej. 2012).

4 Comprendemos contact zones en el sentido de M. Pratt: "[...] where cultures meet, clash and grapple with each other, often in contexts of highly asymmetrical relations of power [...]" (Pratt 1991, 34).

5 Este subcapítulo se basa en las canciones siguientes: "Ponte en mi piel” (1992) de El Chojín; "Clandestino" (1998) de Manu Chao; "Vientos del sur" (2001) de La Fuga; "Sin papeles" (2003) de Che Sudaka; "Tierra prometida” (2005) de Nach; "Sin solución” (2005) de Canteca de Macao; "Permanecer hoy, pensando en el ayer" (2008) de Puño en Boka; "Idas y venidas" (2007) de Jesnac.

6 Se trata de unas 'canciones de rol' ("Rollenlieder") en que el artista adopta la perspectiva de otra persona.

7 "Clandestino" de Manu Chao; "Tierra prometida" de Nach; "Idas y venidas" de Jesnac.

$8 \mathrm{http} / /$ www.songtexte.com/songtext/manu-chao/clandestino-5bc6b730.html (consulta 10.12.2017).

$9 \mathrm{http}: / /$ www.songtexte.com/songtext/che-sudaka/sin-papeles-bca25ce.html (consulta 10.12.2017).

10 http://musicayoutube.blogspot.co.at/2010/08/jesnac-idas-y-venidas.html (consulta 10.12.2017).

$11 \mathrm{http}: /$ www.songtexte.com/songtext/nach-scratch/tierra-prometida-4bcd5722.html y https:// www.youtube.com/watch?v=NVHtzgSZp2o (consulta 10.02.2017).

12 Stuart Green subraya que en el rap de mensaje ("message rap”) la música es muchas veces muy simple para focalizar en el flow y en el contenido del rap (Green 2013, 515).

13 Aquí y en las citas de canciones siguientes cursivas nuestras.

14 http://www.songtexte.com/songtext/el-chojin/ponte-en-mi-piel-con-995-43cbebcf.html (consulta 10.12.2017).

15 https:/www.letras.com/barricada/1003052/ (consulta 10.12.2017).

16 Cf. también "No os dejan entrar" (1999) de Frank T - "acecho fronterizo”, "poli”, "suben muros, suben alambradas / suben más obstáculos”, “cruzar la frontera”. Única canción del corpus que se refiere al pasado colonial de muchos países africanos y a su descolonización como razones de sus problemas actuales.

17 https://www.quedeletras.com/letra-oveja-negra/barricada/5491.html (consulta 10.12.2017). 
18 Por un lado, es la fase en que se construyeron y mejoraron las vallas de 'protección' en Ceuta y Melilla, por otro se instaló a partir de 2000 el Sistema Integrado de Vigilancia Exterior (SIVE) para poder controlar mejor las fronteras.

19 P.ej. Celtas Cortos, "El emigrante", 1996; Manu Chao, "Clandestino", 1998; Nach, "Tierra prometida”, 2005.

20 Salta a los ojos el gran número de canciones antirracistas. P.ej. Benito Kamelas, "No hay color", 1999; Reincidentes, "Paisa (la canción del estrecho)", 1993; Chojín, "Mami el negro está rabioso", 1999, "Yo no soy de esos" y "Cara sucia", 2002, "Rap vs. racismo", 2011; Hamlet, "Racismo es desigualdad", 1996; Frank T, "Sabio joven negro estudiante", 1996, "Humor negro" y "Magia negra”, 2010.

21 https://www.youtube.com/watch?v=0TamvrMZl4g (consulta 10.12.2017).

22 Se realizó una nueva versión del clip en 2011, en Arizona.

23 Primer plano (Close up): encuadre de una figura humana por debajo de la clavícula. El rostro del actor llena la pantalla. Tiene la facultad de introducirnos en la psicología del personaje. Con este encuadre se llega a uno de los extremos del lenguaje visual: los objetos crecen hasta alcanzar proporciones desmesuradas y se muestran los detalles (ojos, boca, etc.).

Semiprimer plano (Semi close up shot): concentra la atención del espectador en un elemento muy concreto, de forma que sea imposible que lo pase por alto. Si se refiere al cuerpo humano, este tipo de encuadre nos mostrará una cabeza llenando completamente el formato de la imagen. Desde el punto de vista narrativo nos puede transmitir información sobre los sentimientos, analiza psicológicamente las situaciones y describe con detenimiento a los personajes.

24 A los teóricos postcoloniales como G. Spivak esta voluntad de "hablar en lugar de" les parece muy problemático porque mantiene y no deconstruye la asimetría de poder existente.

25 Cf. también Frank T. en la misma entrevista: "Yo sé lo que es ir por Madrid en el metro y ser el único negro. Esto yo lo viví a finales de los ochenta y principios de los noventa.” (Green 2011, 172)

26 "Con trece años ya empezó a pararme la policía." (Green 2011, 179)

27 Entrevista con El Chojín, www.youtube.com/watch?v=oGalezcOVXY (consulta 20.03.2017). Otras canciones que se dedican a la España transcultural: "Mestizaje" (2000) de SKA-P; "Babel” (2001) de Pedro Guerra; "Geografía” (2003) de La Oreja de Van Gogh.

28 Peau noire, masques blancs, publicado en 1952 - es decir en plena época colonialista - es considerado por varios teóricos postcoloniales como texto fundador. En el primer capítulo Fanon discute la manera de hablar de los franceses con los procedentes de regiones periféricas (como las islas Martinica y Guadalupe) o países colonizados. Aparecen las mismas preguntas que las mencionadas por El Chojín.

29 Stuart Green interpreta el término como referencia a Malcolm X, uno de los miembros más conocidos de la Nation of Islam, que se sirvieron de la X para subrayar la violencia padecida por sus antepasados cuando recibieron nuevos nombres por los negreros (Green 2013, 510). Habla también de un "homage to black culture and politics" (512).

$30 \mathrm{http} / /$ www.songtexte.com/songtext/frank-t/la-rebelion-de-los-xisianos-3b8798f4.html (consulta 10.12.2017). 
31 Cf. también "El tiempo de los intrusos", también en el álbum Los pájaros no pueden vivir en el agua porque no son peces (1998).

32 https://www.musica.com/letras.asp?letra=1776744 (consulta 10.12.2017).

33 "mil hablas y colores; de acentos diferentes", "crisol multilingüístico".

34 Green hace notar que ese término se encuentra en varias canciones de rap de Frank T. ("El amor", 1999) y El Chojín ("No me altero", 2000).

35 El Chojin en "Ponte en mi piel" (1992). Cf. también Ska-P en "Mestizaje" (2000): "No fronteras, no banderas, no a la autoridad / no riqueza, no pobreza, no desigualdad / rompamos la utopía, dejemos de soñar, / arriba el mestizaje, convivir en colectividad / Gritaré que ardan las banderas por la fraternidad / que caiga el patriotismo y la hostilidad racial / cultura popular...”, http://www.songtexte.com/songtext/ska-p/mestizaje-53c34bb1.html (consulta 10.12.2017).

\section{Bibliografía}

Bernecker, Walther: Spanien-Handbuch. Geschichte und Gegenwart. Tübingen/Basel: A. Francke, 2006.

Bermúdez, Silvia: "Encrucijadas raciales y políticas identitarias: El Chojín y la función social del rap en español”. In: Colmeiro, José (ed.): Encrucijadas globales. Redefinir España en el siglo XXI. Madrid/Frankfurt am Main: Iberoamericana/Vervuert, 2015, 107-123.

Colmeiro, José (ed.): Encrucijadas globales. Redefinir España en el siglo XXI. Madrid/Frankfurt a.M.: Iberoamericana/Vervuert, 2015.

Deveney, Thomas G.: Migration in Contemporary Hispanic Cinema. Lanham: Scarecrow Press, 2012.

Do Mar Castro Varela, María / Dhawan, Nikita: Postkoloniale Theorie: eine kritische Einführung. Bielefeld: transcript, 2005.

El Chojin/Reyes, Francisco: RAP. 25 años de rimas. Un recorrido por la historia del rap en España. Barcelona: Viceversa, 2010.

Frantz, Fanon: Peau noire, masques blancs. Paris: Seuil, 1975.

Gramsci, Antonio: Gefängnishefte. Kritische Gesamtausgabe. Ed. y trad. Klaus Bochmann y Wolfgang Fritz Haug. Hamburg/Berlin: Argument Verlag, 2012.

Green, Stuart: “¿Cómo puedes ser tan negro? Rap y racismo en España. Entrevista con Frank T y El Chojín”. In: Arizona Journal of Hispanic Cultural Studies 15 (2011), 165-186.

Green, Stuart: "The Musical Roots of the Spanish Black Atlantic: The Performance of Identities in the Rap of Frank T and El Chojín”. In: Popular Music and Society 36,4 (2013), 505-522.

Kreienbrink, Axel: "Spanien als Einwanderungsland - Eine Zwischenbilanz nach zwei Jahrzehnten". In: Bernecker, Walther (ed.): Spanien heute. Politik - Wirtschaft - Kultur. Frankfurt a. Main: Vervuert, 2008, 243-270.

Landry, Donna/Maclean, Gerald: The Spivak Reader. London: Routledge, 1995.

Llano Camacho, Isabel: "Bailando la diferencia: identidades culturales y música salsa en Barcelona". In: Periferia: revista de investigación y formación en antropología 20,2 (2015), 161-177. 
Llano Camacho, Isabel: La salsa en Barcelona: inmigración, identidad, músicas latinas y baile. Tesis de doctorado. Universitat Autònoma de Barcelona 2015.

López-Aguilera, Ana M.: "Cine e inmigración: espacios de inclusión y de exclusión”. In: https:// digitalcommons.unl.edu/cgi/viewcontent.cgi?article=1007\&context=modlangdiss (consulta 11.06.2018).

Mathis, Ursula: Existenzialismus und französisches Chanson. Wien: Verlag der Österreichischen Akademie der Wissenschaften, 1984.

Martínez Casas, María: “Autenticidad enunciativa y sociosemántica del pop-rock en español”. In: ATeM 1 (2016), https://webapp.uibk.ac.at/ ojs2/index.php/ATeM/article/view/1656 (consulta 27.02.2017).

Oberhuber, Andrea: Chanson(s) de femme(s). Entwicklung und Typologie des weiblichen Chansons in Frankreich 1968-1993. Berlin: Erich Schmidt Verlag, 1995.

Ortega-Rivera, Enrique / Domingo I Valls, Andreu / Sabater Coll, Albert: "La emigración española en tiempos de crisis y austeridad”. In: Scripta Nova XXX (2016), 1-29.

Ortiz, Fernando: Contrapunteo cubano del tobacco y el azúcar. Madrid: Cátedra, 2002.

Ortiz, Fernando: "Los factores de la cubanidad". In: Revista Bimestre Cubana V, XLV,2 (1940), 161186, http://www.perfiles.cult.cu/articulos/factores_cubanidad.pdf (consulta 10.12.2017).

Peralta García, Lidia: Los nuevos héroes del siglo XXI: Las migraciones subsaharianas vistas por el cine en España y África. Barcelona: Editorial UOC, 2016.

Pratt, Mary Louise: "Arts of the Contact Zone”. In: Profession (1991), 33-40.

Pujante Cascales, Basilio: "La retórica del rap. Análisis de las figuras retóricas en las letras de Violadores del Verso.” In: Revista electrónica de estudios fllológicos (2009), www.tonosdigital.es/ojs/index. php/tonos/article/viewFile/312/232 (consulta 28.02.2017).

Sánchez Fuarros, Ínigo: Cubaneando en Barcelona. Madrid: Editorial CSIC, 2012.

Sánchez Fuarros, Íñigo: "Music and Migration in Multicultural Spain”. In: Martínez, Silvia / Fouce, Héctor: Made in Spain. Studies in Popular Music. New York/London: Routledge, 2013, 144-153.

Spivak, Gayatri: “Can the Subaltern Speak?” In: Nelson, Cary / Grossberg, Larry (eds): Marxism and the Interpretation of Culture. Urbana: University of Illionois Press, 1988, 66-111.

Steyerl, Hito: “Die Gegenwart der Subalternen”. In: Spivak, Gayatri Chacravorty: Can the subaltern speak? Postkolonialität und subalterne Artikulation, Wien u.a.: Turia + Kant, 2008, 7-16.

\section{Páginas web}

http://frontex.europa.eu/trends-and-routes/migratory-routes-map/ (consulta 05.01.2017).

"Entrevista con El Chojín”. In: Noche sin Tregua, www.youtube.com/watch?v=oGalezcOVXY (consulta 20.03.2017). 


\section{Discografía y filmografía}

Barricada: Balas blancas. Universal B000006SQV, 1992 (CD).

Barricada: Acción directa. Dro B000HOLULW, 2007 (CD).

Che Sudaka: Alerta Bihotza. K Industria B000AY2K6S, 2005 (CD).

El Chojín: Cuando hay obstáculos. BOA 23002028, 2002 (CD).

El Chojín: Solo para adultos. BOA 23002023, 2001 (CD).

Ella baila sola: Ella baila sola. Plg Group B004966TBA, 2010 (CD).

Frank T: Sonrian por favor. Warner B000P29900, 2008 (CD).

Frank T: Frankattack. Dro B000HOMS2W, 2008 (CD).

Frank T: Los pájaros no pueden vivir en el agua porque no son peces. Dro B000HOMS22, 2007 (CD). Jesnac: "Idas y venidas". In: http://musicayoutube.blogspot.co.at/2010/08/jesnac-idas-y-venidas. html (consulta 10.12.2017).

La Fuga: A las doce. Dro B0006NLJQ0, 2007 (CD).

Manu Chao: Clandestino. Because Music B00F2N3MU0, 2013 (CD).

Manu Chao: "Clandestino. Video oficial". In: https:/www.dailymotion.com/video/x1t1uw (consulta 10.12.2017).

Nach: Ars Magna/Miradas. Mis B00TPN1AT8, 2015 (CD).

\section{Apéndice: Corpus}

\section{Nombre}

Amistades Peligrosas

El Chojín

El Chojín

Barricada

Reincidentes

Joan Manuel Serrat

Ella baila sola

Celtas Cortos

Hamlet

Frank T.

Revólver

Soledad Bravo

Los Cabales

Manu Chao

Frank T.

Frank T.

Frank T.

Frank T.

\section{Título}

Africanos en Madrid

Ponte en mi piel

Sí, Buana

Oveja negra

Paisa la canción del estrecho

Te guste o no

Qué se te escapa el negro

El emigrante

Racismo es desigualdad

Sabio joven negro estudiante

Calle mayor

Punto y raya

Sangre emigrante

Clandestino

El tiempo de los intrusos

La rebelión de los x'isianos

El amor

No os dejan entrar
Año de publicación

1991*

1992

1992

1992

1993

$1994^{*}$

1996

1996

1996

1996

1996*

$1997^{*}$

$1997^{*}$

1998

1998

1998

1999

1999 


\section{Nombre}

Benito Kamelas

Victor Manuel

El Chojín

Ska-P

El Chojín

Ska-P

Ella Baila Sola

La Fuga

Pedro Guerra

Manu Chao

El Chojín

El Chojín

Antonio Martínez

Che Sudaka

La Oreja de Van Gogh

Amparanoia

Nach

Canteca de Macao

Barricada

Frank T.

La Oreja de Van Gogh

Hakim

Algiva

Jesnac

Chambao

Ismael Serrano

Estrella Morente

Campanillas Blues Band

Puño en Boka

\section{ECUAPOP}

El Chojín

Frank T.

Frank T.

El Chojín

\section{Título}

No hay color

Vienen del sur

Mami el negro está rabioso

Mestizaje

No me altero

Planeta Eskoria

La patera

Vientos del sur

Babel

Me gustas tú

Cara sucia

Yo no soy de esos

Trova el emigrante

Sin papeles

Geografía

Somos viento

Tierra prometida

Sin solución

Víctima

La Nueva España

Vuelve

Yo soy aquel morito

Los ojos del faro

Idas y venidas

Papeles mojados

Zamba del emigrante

con Mercedes Sosa

Vente conmigo

Pateras en el mar

Permanecer hoy,

pensando en el ayer

Permanecer hoy,

pensando en el ayer

La perversión del lenguaje

Humor negro

Magia negra

Rap vs. racismo
Año de publicación

1999

$1999 *$

1999

2000

2000

$2000^{*}$

$2000^{*}$

2001

2001

$2001^{*}$

2002

2002

$2002^{*}$

2003

2003

$2004^{*}$

2005

2005

2006

2006

2006*

$2006^{*}$

2006*

2007

2007*

2007*

2007*

2007*

2008

$2008^{*}$

2009*

2010

2010

2011

* no citado en el artículo 